Published in final edited form as:

Pediatr Dermatol. 2017 March ; 34(2): 197-198. doi:10.1111/pde.13056.

\title{
A cross-sectional study evaluating skin, hair, nail and bone disease in patients with Focal Dermal Hypoplasia
}

\author{
Nicole S. Gunasekera, BA ${ }^{1,3}$, Joan K. Divito, BS ${ }^{1}$, Thomas S. Kupper, MD ${ }^{1,3}$, Jennifer \\ Huang, $\mathbf{M D}^{2,3}$, and Sherrie J. Divito, MD, $\mathbf{P h D}^{1,3}$ \\ 1Department of Dermatology, Brigham and Women's Hospital, Boston, MA 02115 \\ 2Program in Dermatology, Division of Allergy and Immunology, Boston Children's Hospital, \\ Boston, MA 02115 \\ ${ }^{3}$ Harvard Medical School, Boston, MA 02115
}

\begin{abstract}
Focal Dermal Hypoplasia (FDH) is an X-linked dominant disease characterized by dermal thinning and fat herniation, with other ectodermal and mesodermal abnormalities. There is limited literature regarding symptomatology and progression of skin, hair and nail disease. Risk of bone fragility too has not been explored. This cross-sectional survey-based study explores these gaps in knowledge, and provides direction for future avenues of research in FDH.
\end{abstract}

\section{Keywords \\ focal dermal hypoplasia; goltz syndrome; genodermatosis}

Focal dermal hypoplasia (FDH) is an X-linked dominant disease of ectodermal and mesodermal tissues, without any definitive treatment. ${ }^{1-5} \mathrm{FDH}$ is characterized by dermal hypoplasia with additional skin, hair and nail involvement possible. Current literature is limited regarding integumentary symptoms and disease progression. FDH can also manifest in multiple other organ systems including bone. ${ }^{1,2,5}$ Whether FHD patients are predisposed to bone fragility is unknown. ${ }^{1}$

We designed a cross-sectional study based on a 30-item questionnaire to investigate skin, hair, nail and bone disease in FDH patients, which was administered at the National Foundation for Ectodermal Dysplasias (NFED) Family Conference, FDH Session, July 24th 2015. Participation was optional and all responses anonymous. Proof of genetic diagnosis was not required. Parent(s)/guardian(s) completed the questionnaire on behalf of children. This study was approved by our Institutional Review Board. All returned surveys were

\footnotetext{
Corresponding Author: Sherrie J. Divito, MD, PhD, Instructor, Harvard Medical School, Associate Physician, Brigham and Women's Hospital, Department of Dermatology, Harvard Institutes of Medicine, Rm 660, 77 Ave Louis Pasteur, Boston, MA 02115, Phone: 617-525-5550, sdivito@bwh.harvard.edu.

This study was IRB approved.

All authors provide consent for publication.

Conflict of Interest: The authors have no conflicts of interest to declare
} 
included in analysis. Unanswered questions and responses specifying "I don't know" were treated as missing data, and were excluded from analysis of that question.

Seventeen patients/families participated in the study (Table 1). Median patient age was 9 years (range 1.6 - 57 years); 16 patients were $\leq 16$ years-old. Eleven participants were female, five were male ( 1 unanswered). Three study children experienced multiple fractures (Table 1). Four of 17 children underwent bone density testing, though only 2 knew test outcome. An 11 year-old female with history of both arm and pelvic fracture tested positive for osteoporosis. This last observation raises concern that bone strength may be affected in FDH patients, and warrants further investigation. Given the safety profile of calcium and vitamin D, clinicians might consider supplementation in FDH patients.

All participants reported skin and nail involvement (Table 2). Twelve of 16 participants reported scalp/hair involvement. The majority of respondents endorsed skin/scalp symptoms (pruritus, burning, stinging, and tenderness). Five of 15 participants endorsed nail pain.

The majority of respondents reported skin disease progression. Progression included (i) increased surface area involved, (ii) worsened severity of already involved skin, (iii) worsened symptoms, and/or (iv) new papillomas (Table 2). Six of 17 participants endorsed progression of nail disease. Four of 16 participants endorsed worsening scalp symptoms, though none reported increased alopecia with time.

All 17 participants reported experiencing flares of skin disease, 5 of 17 nail disease, and 3 of 17 hair disease (Table 2). Commonly endorsed triggers included physical illness, heat/ humidity, cold and/or dry air, emotional stress, and exercise. One respondent reported food allergies and one reported puberty as triggers.

The enclosed data indicate that in FDH patients, skin, scalp/hair and nail disease are prevalent, commonly flare, and for many patients progress over time. This suggests that clinicians might consider counseling patients/families about potential flare triggers and temper patient/family expectations. Importantly, participants overwhelmingly identified skin manifestations as the single most important aspect of disease that they wish could be improved (data not shown).

Study limitations include small sample size, selection bias, and recall bias. Despite these limitations, these data provide guidance regarding expectations for clinicians, patients, and families, while also suggesting future avenues of research.

\section{Acknowledgments}

Funding source: National Foundation for Ectodermal Dysplasias

The authors would like to thank the National Foundation for Ectodermal Dysplasias for making this research possible and all the FDH patients and families that participated in this study.

\section{References}

1. Goltz RW. Focal dermal hypoplasia syndrome. An update. Archives of dermatology. Aug; 1992 128(8):1108-1111. [PubMed: 1497368] 
2. Grzeschik KH, Bornholdt D, Oeffner F, et al. Deficiency of PORCN, a regulator of Wnt signaling, is associated with focal dermal hypoplasia. Nature genetics Jul. 2007; 39(7):833-835.

3. Wang X, Reid Sutton V, Omar Peraza-Llanes J, et al. Mutations in X-linked PORCN, a putative regulator of Wnt signaling, cause focal dermal hypoplasia. Nature genetics Jul. 2007; 39(7):836838 .

4. Sheu J, Divito SJ, Hoffman EP, Frank NY, Merola JF. Mosaic focal dermal hypoplasia caused by a novel somatic mutation in PORCN gene detected in affected skin. British Journal of Dermatology. 2015

5. Hall EH, Terezhalmy GT. Focal dermal hypoplasia syndrome. Case report and literature review. Journal of the American Academy of Dermatology Sep. 1983; 9(3):443-451. 
Table 1

Demographic and bone health data of survey respondents.

\begin{tabular}{|l|l|l|l|l|}
\hline Age (years) & Gender & Number/location of fracture(s) & Bone density testing/results & Treatment with calcium + vitamin D \\
\hline 1.6 & F & & & \\
\hline 3 & M & & & \\
\hline 5 & F & & & \\
\hline 5 & F & & Yes/Unknown & \\
\hline 7 & F & 1, arm & & \\
\hline 7 & $*$ & 2, arm and leg & Yes/Negative & Yes \\
\hline 9 & M & & & \\
\hline 9 & M & & & \\
\hline 9 & F & & & \\
\hline 10 & F & & & Yes \# \\
\hline 11 & F & 2, arm and pelvis & Yes/Positive & \\
\hline 11 & F & & & \\
\hline 14 & F & & & \\
\hline 14 & F & & & \\
\hline 15 & F & & & \\
\hline 16 & M & 4,1 arm and 3 leg & & \\
\hline 57 & M & 2, finger and toe & & \\
\hline
\end{tabular}

* Unanswered

${ }^{\#}$ Also considering bisphosphonate or hormone injections 


\section{Table 2}

Skin, hair and nail involvement in FDH patients.

\begin{tabular}{|l|l|l|l|}
\hline & $\begin{array}{l}\text { No. of respondents reporting disease/ } \\
\text { Total no. of respondents }(\%)\end{array}$ & $\begin{array}{l}\text { No. of respondents reporting disease } \\
\text { progression/Total no. of respondents } \\
(\%)\end{array}$ & $\begin{array}{l}\text { No. of respondents reporting disease } \\
\text { flares/Total no. of respondents (\%) }\end{array}$ \\
\hline Skin & $17 / 17(100 \%)$ & $12 / 17(\%)$ & $17 / 17(100 \%)$ \\
\hline Scalp/Hair & $12 / 16^{\#}(75 \%)$ & $4 / 16^{\#}(25 \%)$ & $3 / 17(18 \%)$ \\
\hline Nail & $17 / 17(100 \%)$ & $6 / 17(35 \%)$ & $5 / 17(29 \%)$ \\
\hline
\end{tabular}

\begin{tabular}{|l|l|l|l|}
\hline & $\begin{array}{l}\text { No. of respondents reporting symptoms/ } \\
\text { Total no. of respondents }\end{array}$ & $\begin{array}{l}\text { No. of respondents endorsing triggers of } \\
\text { flares/Total no. of respondents }\end{array}$ \\
\hline Skin/Scalp Symptoms & & Triggers & \\
\hline Pruritus & $12 / 17(71 \%)$ & Heat/humidity & $15 / 16^{\#}(94 \%)$ \\
\hline Burning & $11 / 15^{\# *}(73 \%)$ & Cold/dry air & $15 / 16^{\#}(94 \%)$ \\
\hline Stinging & $7 / 14^{\# * *}(50 \%)$ & Emotional stress & $13 / 15^{\# *}$ \\
\hline Tenderness/Soreness & $10 / 15^{\# *}(67 \%)$ & Physical illness & $16 / 16^{*}$ \\
\hline Nail Pain & $5 / 15^{\# *}(33 \%)$ & Exercise & $11 / 12^{\# * * * *}$ \\
\hline
\end{tabular}

one,

*** two, or

*****

four participants responded "I don't know" to this question

\#

\# one respondent did not answer this question 